\section{Plötzlicher Visusverlust}

VON H. S. FÜEßL

Ein 76-jähriger Mann kommt am späten Vormittag in Begleitung seiner Frau in die Praxis und berichtet, dass er seit dem Morgen auf dem rechten Auge nichts mehr sehen würde. Er sei aufgewacht und beim Gang zur Toilette heftig mit dem rechten Fuß gegen einen Stuhl gestoßen, offensichtlich weil sein Gesichtsfeld von rechts her eingeschränkt sei. Wenn er sich das linke Auge zuhält, sei alles schwarz. Schmerzen habe er nicht. Sie wissen, dass der Patient seit vielen Jahren eine mäßig eingestellte Hypertonie und einen Typ-2-Diabetes hat.

\section{Situation und Symptomatik}

Dem schlagartigen kompletten Sehverlust liegt meistens eine Durchblutungsstörung zugrunde, z. B. ein Zentralarterienverschluss (Abb. 1). Er trifft in der Regel ältere Patienten mit vaskulären Risikofaktoren. Visusverluste, die sich im Lauf von Stunden entwickeln oder bei denen noch ein Lichteindruck, manchmal in Form bizarrer optischer Sensationen wie Blitz- oder Funkensehen, Rußregen, schwarzer Vorhang, Mouches volantes, Nebel- oder Schleierwahrnehmung oder rötliche Verfärbungen bestehen, lassen eher an einen Zentralvenenverschluss (Abb. 2), eine Ablatio retinae, eine Glaskörperblutung oder eine akute ischämische Optikusneuropathie denken. Liegen Schmerzen vor, kommen auch eine Riesenzellarteriitis, eine Neuritis nervi optici oder ein akuter Glaukomanfall (Abb. 3) in Betracht.

\section{Sofortdiagnostik}

Grobe Prüfung des Sehvermögens nach Abdecken des Partnerauges und grobe Gesichtsfeldbestimmung. Befühlen des Bulbus - steinhart? Injektionen? Pupillenweite? Prüfung der Pupillenreaktion auf Licht: bei Zentralarterienverschluss direkte Lichtreaktion aufgehoben, indirekte (d. h. Belichtung des gesunden Auges) regelrecht vorhanden.

\section{Therapeutische Maßnahmen}

Notfallmäßige Überweisung an Spezialisten, Augenarzt oder besser Augenklinik. Zeit des Transportes überbrücken mit ggf. RR-Senkung (falls massiv erhöht), z. B. Nitrendipin, i. v. Zugang mit Ringer- oder HAES-Lösung, Furosemid $40 \mathrm{mg}$ i. v.

\section{Woran noch denken, was noch tun?}

Der Verdacht auf einen akuten Gefäßverschluss ist ohne weitere diagnostische Hilfsmittel immer gegeben. Daher sollte ein Patient mit plötzlichem Visusverlust wie bei zerebraler Ischämie behandelt werden. Bestenfalls besteht inner-
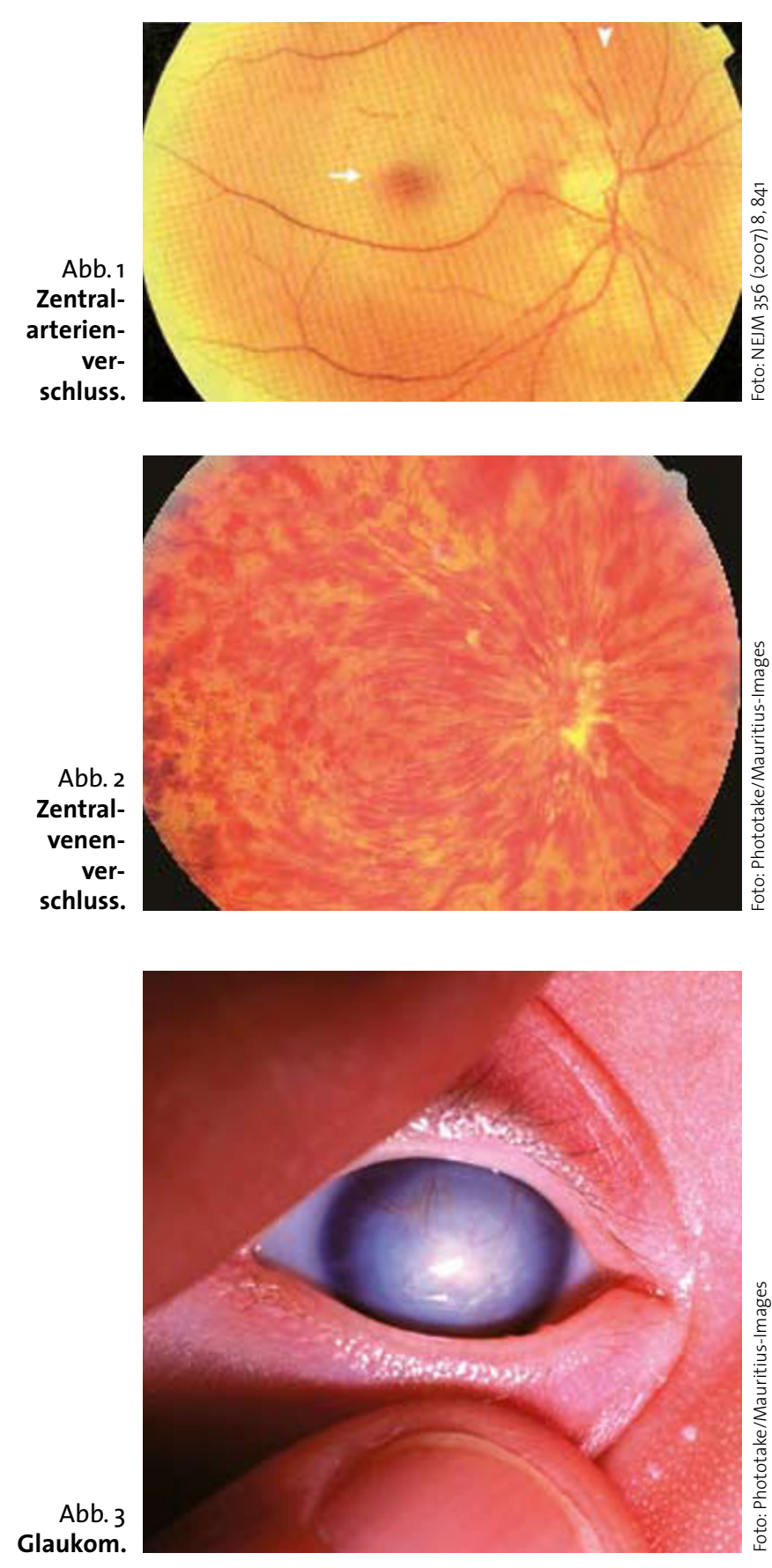

halb von vier bis sechs Stunden nach Wiedereröffnung des Gefäßes die Chance auf eine Funktionsverbesserung. Über die Lysebehandlung mit Urokinase liegen präliminäre Daten vor, die auf eine Überlegenheit gegenüber dem rein konservativen Vorgehen hinweisen.

\section{Anschrift des Verfassers:}

Prof. Dr. med. H. S. FüeßI, Leiter Somatischer Querschnittsbereich, Isar-Amper-Klinikum, Klinikum München-Ost, Ringstr. 33a, D-85540 Haar, E-Mail: Fueess|@Krankenhaus-Haar.de 